\title{
Regional Economic Integration and the Location of Multinational Firms
}

\author{
Carlo Altomonte
}

Università Bocconi

\begin{abstract}
A theoretical model of international location is applied to a process of regional economic integration in which a set of countries mutually removes barriers to trade and investment, thus overcoming the traditional 'hub and spoke' setup of regional agreements. The theoretical results are matched with actual trade and foreign investment data from a sample of some 4,200 multinational firms who have invested in Central and Eastern Europe over the 1990-1999 period. Controlling for the effects of the reduction in trade barriers through a proper specification of a gravity model, it is found that the conventional outcome of an agglomeration of economic activities in the centre of the integrating area does not necessarily hold. Multilateral regional integration agreements can act as an important dispersion force significantly driving the location of multinational firms. A panel probit econometric exercise confirms the findings. JEL no. F12, F15, F21

Keywords: Economic integration; FDI
\end{abstract}

\section{Introduction}

The international economic environment in the last decade has been characterized, among others, by a surge of Regional Integration Agreements (RIAs), i.e. groupings of countries formed with the objective of reducing barriers to trade between members. The World Trade Organization (WTO) reports that, out of the total 250 regional agreements of which it had evidence up to December 2002, 130 were notified to the Organization after January 1995. Nowadays, over 170 RIAs are in force, while an additional 70

Remark: The paper greatly benefited from comments by Italo Colantone, Thierry Mayer, Gianmarco Ottaviano, Reinhilde Veugelers, the managing editor (Harmen Lehment), an anonymous referee, and seminar participants at Bocconi, the 29th EARIE Conference, the 5th European Trade Study Group meeting and the 1st Conference of the Euro-Latin Study Network on Integration and Trade. The usual disclaimer applies. Please address correspondence to Carlo Altomonte, IEP - Via Gobbi, 5, 20136 Milan, Italy; e-mail: carlo.altomonte@unibocconi.it 
are estimated to be operational although not yet notified. ${ }^{1}$ The same WTO reports that, once agreements currently under negotiation are concluded, the total number of RIAs in force might well approach 300 .

Not surprisingly, the evolution of RIAs has stimulated a revamp of the economic literature studying the phenomenon of economic integration. Such a renewed interest has also been fostered by the progresses achieved in our understanding of the gravity models of international trade, now more thoroughly founded theoretically and better specified from an econometric point of view (e.g. Anderson and Van Wincoop 2003; Egger and Pfaffermayr 2003). However, recent studies have mainly concentrated on the trade effects of RIAs, i.e. a refined analysis of the Vinerian concepts of trade creation and trade diversion (e.g. Carrére 2006; Romalis 2005), but they have only marginally touched upon the relationship between foreign direct investment (FDI) and regional economic integration, which remains a more controversial issue.

In fact, in a two-countries setup (Carr et al. 2001; Markusen and Venables 1998, 2000; Markusen 2002) a decrease in trade barriers associated to the creation of a RIA would ceteris paribus generate a decrease in FDI, since the latter are undertaken to avoid facing transport costs and tariffs when serving the foreign market. ${ }^{2}$ If instead FDI are mainly driven by comparative advantages (e.g. firms which geographically fragment their production by stages located in different countries to exploit cheaper labour costs), the correlation between the establishment of RIAs and foreign investment flows becomes positive, since FDI will tend to increase once trade barriers are removed. In the traditional two-countries models, therefore, the relationship between FDI and a process of regional economic integration is a priori not univocal.

The ambiguity is partially solved within a multicountry framework: both Baldwin and Venables (1995) and Motta and Norman (1996) suggest a 'production shifting' effect possibly taking place as a consequence of RIAs. The idea is that, in a regional integration agreement that reduces trade barriers between member countries while maintaining barriers with

\footnotetext{
1 Regional integration agreements are an exception to the most-favoured nation clause. As such, they have to be notified to the WTO under the proceedings of Art. XXIV of the GATT agreement.

2 FDI in these models arise when countries are similar in size and trade costs are relatively high. Markusen (2002) reports, among the main stylized facts on FDI, evidence that "FDI is positively related to the existence of trade barriers" (Markusen 2002: 7). The latter is also known as the 'tariff-jumping' attitude of FDI analysed, among others, in Motta and Norman (1996).
} 
respect to nonmembers, the market access of firms operating within the region is improved. Therefore, there is an incentive to locate in member countries (FDI creation) at the detriment of other potential host countries (FDI diversion) which do not participate to the RIA. By and large, the latter intuition seems to be supported by the empirical evidence, with several studies finding a positive impact of regional integration on FDI flows. ${ }^{3}$

Less clear-cut is however the relationship between a process of economic integration and the location of FDI within the integrating area. From a theoretical point of view, Puga and Venables (1997) apply a core-periphery model of international location to a multicountry case and conclude, among other findings, that in a 'hub and spokes' arrangement of trade liberalization ${ }^{4}$ firms will tend to concentrate in the 'hub', since firms located in 'spoke' countries are penalized from a lower demand by both consumers and firms in other 'spokes', as compared to that enjoyed by 'hub' firms. The latter theoretical result has been confirmed and generalized by Baldwin et al. (2003), who have developed an analytical model where both the FDI creation (or production shifting) and the FDI diversion effect are a corollary of the home market effect arising in a standard economic geography model. Within their analytical framework, Baldwin et al. (2003) are able to characterize what they call a 'two-tier home market effect': as a group of countries enters in a RIA, the region experiences FDI creation induced by the home market effect; however, as integration deepens, a second home market effect, internal to the bloc, tends to favour the largest bloc members as an industrial location, with a core-periphery pattern arising within the RIA.

The available empirical evidence within RIAs is not fully supportive of the core-periphery locational outcome postulated by the economic theory. The more recent evidence, especially in the US or the EU case, is certainly consistent with an investment creation effect associated to the setup of

\footnotetext{
3 Among others, Norman and Motta (1993) have analysed the effects of the free trade area between Eastern European countries on the strategies of external firms, showing that both market growth and improved market accessibility cause outside firms to change their strategies from exporting to FDI. Blomström and Kokko (1997) provide three studies focusing on different kinds of regional integration: North-North integration (Canada joining CUSFTA), North-South integration (Mexico's accession to NAFTA), and South-South integration (MERCOSUR). The same UNCTAD World Investment Report - 2003 presents several case studies of multinational enterprises which have invested as a result of a process of regional economic integration.

4 'Hub and spokes' agreements give one country (the 'hub') a better access to other countries (the 'spokes') than these have to each other. Examples of these arrangements are the agreements concluded in the 90 s between the European Union and each of the Central and Eastern European countries or each of the South Mediterranean countries.
} 
regional integration agreements; however, there seems to be also a tendency of economic activities to relocate towards the low-cost peripheries, rather than the core, of the integrating regions (e.g. Nijkamp et al. (2003) for the EU case or Hanson (1996) for the US one).

Such a mismatch can be interpreted in light of the most recent theories of FDI, which have emphasized the 'complex' integration strategies of multinational firms (e.g. Ekholm et al. 2003; Yeaple 2003; Grossman et al. 2006). In particular, this strand of research departs from the restrictive partition of horizontal vs. vertical multinationals, and emphasizes the importance of third-country effects in the location strategies of multinational firms: apart from the traditional market access argument, it might be optimal for the same multinational to set up export platforms in other host countries (eventually characterized by cheaper factors of production), and thus serve consumers in the entire RIA from that location.

Since the latter argument seems to be more consistent with the empirical evidence, the goal of the paper is thus to reconcile the different theoretical predictions with the actual location choices of multinational firms within RIAs, showing that, once a series of dispersion forces are properly considered within a model of international location, the conventional outcome of an agglomeration of economic activities in the centre of the integrating area does not necessarily hold.

In particular, it is found that a specific configuration of regional integration agreements, where trade is liberalized not only along the 'hub and spokes' dimension, but also across the same 'spokes', can act per se as an important dispersion force. The intuition behind this result is that the creation of such a RIA, in which the entire market is now accessible from every peripheral country, allows firms located in the 'spokes' to exploit their locational advantages (e.g. cheaper labour costs) without suffering a dramatic reduction in the market size that can be served from these locations, as it would be instead the case in a traditional 'hub and spokes' agreement. In other words in this type of RIAs, more and more widespread worldwide, lower opportunity costs (in terms of market access) are incurred when exploiting comparative advantages in the periphery, and thus, consistently with the empirical evidence, there is a tendency to a diffusion of industrial activities across the entire integrating area.

The intuition is empirically tested exploiting a firm level data set of more than 4,200 multinational enterprises (MNEs) that have established production units in Central and Eastern European Countries (CEECs) in the period 1990-1999, a time span during which these countries have ex- 
perienced a process of regional economic integration not only with the European Union (following a typical 'hub and spokes' pattern), but also among themselves.

The paper is organized as follows. Section 2 discusses some features of modern RIAs and lays down the framework of the theoretical relationship between regional economic integration and the location of firms. In Section 3 the theoretical hypotheses are matched with an empirical analysis of the industrial location patterns in the CEECs, exploiting gravity models to recover a proper measure of economic integration. Section 4 validates the identified relationship between industry location and regional integration dynamics through an econometric exercise. Section 5 concludes.

\section{RIAs and the Location of Firms: Theory}

A number of factors might explain the divergence between the theoretical results of location models and the empirical evidence linking the establishment of RIAs to FDI.

First of all, Baldwin et al. (2003) acknowledge that their core-periphery result might change once one allows for any number of strong enough dispersion forces, such as barriers to the relocation of capital, differences in comparative advantages or competition effects, eventually within the emergence of 'complex' integration strategies. A model suited to empirically test the impact of preferential liberalization on the location of industry should thus take these factors into account.

However, a key issue not thoroughly explored by the literature is that the same geographical configuration of RIAs might affect the MNE's integration strategies and thus the industry locational equilibria. In particular, the last generation of regional integration agreements tends to have a multilateral nature, since these agreements combine the traditional 'hub and spokes' bilateral pattern of integration with arrangements in which the 'spokes' enjoy free trade among themselves. Hence, the whole integrated market can be served from any given location within the area. The creation of the North American Free Trade Agreement (NAFTA) has been one of the first examples of these multilateral RIAs. ${ }^{5}$ Firms located in the European

${ }^{5}$ Not surprisingly, the novelty of the NAFTA case has led to a strand of research on the effects of economic integration. With specific reference to the effects on the location of industries, Hanson (1996) finds that the North American Free Trade Agreement has con- 
Union have also been experiencing a similar situation: in this region, in fact, the existing bilateral Europe Agreements between the EU and each of the CEECs have been progressively complemented with the creation among the CEECs of CEFTA, the Central European Free Trade Agreement (see the Appendix for a description of the timing of these agreements). The project of an Asian-Pacific Economic Cooperation (APEC) initiative, the Free Trade Agreement of the Americas (FTAA) and the projected Euro-Med Free Trade Area are all further examples of the recent trend towards the creation of these 'multilateral' RIAs.

The implications of the recently acquired multilateral nature of RIAs for FDI location can be conveniently accounted for by exploiting the same results of Baldwin et al. (2003). Namely, being the FDI creation effect a corollary of the home market effect applied to a multicountry case, the relevant market size to consider in the analysis has to be defined not only in terms of local demand, but also taking into account the demand of nearby markets. ${ }^{6}$ The latter is exactly the channel through which the creation of a multilateral RIA makes it more likely for firms to locate in the periphery of the integrating region, since the opportunity costs in terms of access to nearby markets incurred when exploiting comparative advantages in peripheral countries are lower in multilateral RIAs than in other traditional configurations (e.g. the 'hub and spokes' pattern) of the integration agreements. $^{7}$

tributed to the relocation of manufacturing production in the United States towards the US-Mexican border. Hanson (1999) also provides some factual evidence on how the movement towards free trade in North America has influenced the spatial organization of production in Canada, Mexico or the United States, although no formal testing of hypotheses is performed.

6 The idea that in a multicountry setup one has to consider the shape of the economic space in which the various sources of demand are located was labeled as 'market potential' by Harris (1954), who suggested that the actual demand faced by firms in a given location is not only determined by the size of the local economy, but also by the sum of the market sizes of bordering countries, weighted through a measure of accessibility to all locations, itself a function of both commercial barriers and geographical distance. The concept has recently been revisited by several authors within empirical applications of the economic geography literature. In particular, Davis and Weinstein (2003) have shown that the size of demand in nearby markets, and not only in local markets, significantly matters in investigating home market effects in trade between OECD countries. Baltagi et al. (2007) provide econometric evidence that third-country effects (although not necessarily within a RIA) are important, thus lending support to the undertaking of complex FDI strategies. 7 The effect might depend not only on the new firms which invest in the area as a result of the process of regional integration, but also on the vertical disintegration in the periphery of some activities previously produced by incumbent firms in the hub (offshoring). 
In order to incorporate this intuition into a theoretical framework that can be validated against actual FDI location decisions, it is then convenient to model the profit opportunities available to a firm which decides to invest in a peripheral country of a given RIA.

The utility of a representative consumer in each peripheral country $i$ belonging to a RIA is a CES function depending on the quantity of each variety $h=1, \ldots, n_{j}$ consumed of a differentiated good produced in country $j$ (i.e. in the same country $i$ or in another country $j$ within the same region). In particular, the utility function can be written as

$$
U_{i}=\left(\sum_{j=1}^{N} \sum_{h=1}^{n_{j}}\left(q_{i j h}\right)^{\frac{\sigma-1}{\sigma}}\right)^{\frac{\sigma}{\sigma-1}} \quad \text { with } \sigma>1,
$$

where $q_{i j h}$ denotes the quantity consumed in each country $i$ of the $h$ variety produced in country $j$ and $\sigma$ is the elasticity of substitution across varieties. The production of each variety is subject to increasing returns and monopolistic competition. In particular, the technology is characterized by a single factor of production, labour; the marginal production cost in each country $j$ is denoted $\phi_{j} w_{j}$, where $w$ is the wage and $\phi$ is the inverse of labour productivity, with increasing returns deriving from fixed costs in labour $w_{j} F$. In order to sell its products in country $i$ a multinational firm which has located its production plant in country $j$ has to pay an additional transport $\operatorname{cost} \tau_{i j}$ which takes the usual iceberg form. The budget constraint is given by the expenditures of country $i$ on all $k$ varieties produced in all $j$ countries (including country $i$ ) belonging to the RIA, i.e. $k=\sum_{j} n_{j}$. In particular, denoting $p_{i j}$ as the c.i.f. price of goods imported in country $i$ from country $j$ and $m_{i j}$ as the value of imports from $j$ to $i$, the budget constraint for a representative variety $q_{i j}$ produced in country $j$ and consumed in country $i$ can be written as $M_{i}=\sum_{k} m_{i k}=\sum_{k} q_{i k} p_{i k}$. Following Head and Mayer (2004) it can be shown that the total profit accruing to a firm which would decide to serve all the $N$ countries belonging to the considered RIA from a plant located in country $j$ is:

$$
\pi_{j}=\frac{\left(\phi_{j} w_{j}\right)^{1-\sigma}}{\sigma} \sum_{i=1}^{N} \frac{1}{\sum_{k} n_{k}\left(\phi_{k} w_{k} \tau_{i k}\right)^{1-\sigma}} \tau_{i j}^{1-\sigma} M_{i} .
$$

Such a profit is a decreasing function $(\sigma>1)$ of the production costs $\left(\phi_{j} w_{j}\right)$ in the same country $j$, a decreasing function of the intensity of competition with rivals $\left[\sum_{k} n_{k}\left(\phi_{k} w_{k} \tau_{i k}\right)^{1-\sigma}\right]$, itself increasing with the number of rivals $n_{k}$ 
and decreasing with the production costs $\left(\phi_{k} w_{k} \tau_{s k}\right)$ they face, and finally an increasing function of the market potential $\left(\sum_{i=1}^{N} \tau_{i j}^{1-\sigma} M_{i}\right)$ of country $j$, i.e. the total demand that is accessible from a production plant located in country $j .^{8}$

Equation (2) can be conveniently used to empirically test the likelihood of having foreign investments located within a RIA, since it can be decomposed in three variables all measurable at the (macro) country level: the market potential of country $j$, a measure of the relative costs of country $j$ with respect to the other $N$ countries of the region (i.e. the ratio between the labour costs $\phi_{j} w_{j}$ of country $j$ and those of rival countries $\sum_{k} \phi_{k} w_{k} \tau_{s k}$ ), and the number of competitors $K=\sum_{k} n_{k}$.

In particular, the hypothesis to validate against empirical evidence is that the creation of a multilateral RIA allows firms to exploit through the undertaking of FDI the locational advantages of peripheral countries without necessarily suffering a dramatic reduction in the market size that can be served from these locations, with all these elements now properly formalized in the model.

\section{RIAs and the Location of Firms: Empirical Evidence}

The validation exploits the regional integration agreements created among the EU and the CEECs in the 90s, whose institutional details are reported in the Appendix. In particular, the empirical analysis is based on a firmspecific collection of some 4,200 FDI initiatives in the CEECs in the period 1990-1999, retrieved from the Amadeus database. ${ }^{10}$ The sample contains

${ }^{8}$ As already noted by other authors, imposing $\tau_{i j}^{1-\sigma}=1 / d_{i j}$, i.e. proxying the transport costs with the distance from $j$ to $i$, one would obtain the market potential index originally proposed by Harris (1954).

9 Clearly, in a general equilibrium setup the market potential of the $j$ country in which the firm ultimately decides to locate would be partly endogenous with respect to the firm's positive profits, via the channel of increased wages/expenditures of the workers/consumers. However, in a monopolistic competitive market structure, the size of firms' profits can be assumed to be negligible with respect to each country's total demand. Alternatively, firms can always be assumed to repatriate fully or in part their profits, a liberalization regime typically associated with the setup of RIAs. Hence, it is possible to consider the market potential faced by individual firms as exogenous with respect to their profits, and therefore retain the partial equilibrium setup of the model.

10 Amadeus is a comprehensive, pan-European database developed by a consulting firm, Bureau van Dijck. It contains balance sheet data in time series on 7 million public and private companies in 38 European countries. 
information on the year of entry, country and sector of activity (at the NACE3 level) of each recorded multinational. The correlation coefficient of the sample with official FDI inflows, as reported from UNCTAD along the country/year dimension, is 0.92 and significant at the 1 per cent level.

Apart from the availability of firm-specific FDI data, several reasons support the choice of the EU-CEECs RIA as the testing ground of the theoretical hypothesis. First of all, the complex set of agreements in the area is shaped as a multilateral RIA since, apart from the 'hub and spoke' liberalization of the CEECs with the EU, the same countries of Central and Eastern Europe (the 'spokes') have also liberalized trade among themselves over the same period. As reported in the bottom part of Table 1, the removal of trade restrictions led to significant integration dynamics, with a six-fold increase in trade flows (from 15.5 to 94.1 billion of US dollars) between the EU and the CEECs in the 1990-2000 decade, and a similar increase within the same CEECs (from 2.5 to 15.2 billion of US dollars) over the period.

In addition, in the considered RIA the eventual location of firms in the periphery (the CEECs) is likely to take place in a context virtually devoid of significant local competition, due to the transition of Central and Eastern European countries from plan to market. Strategic considerations in the location decisions of firms can then be assumed as less relevant, consistently with the Dixit-Stiglitz setup of the theoretical model, where the number of rivals is exogenous. For the same reasons, the EU-CEECs RIA also allows for an ideal control of initial conditions, since before 1990 virtually no FDI was permitted in the periphery.

The data provide some preliminary support for the hypothesis that, as regional economic integration proceeds, FDI flows tend to increase in the peripheral areas of a multilateral RIA: the official statistics show in fact that within the EU-CEECs RIA foreign direct investments to the CEECs (the periphery) have increased at an average yearly rate of 50 per cent over the period in which the removal of trade barriers was being implemented (Table 1, first row), while the same figure for the EU-15 has been around 25 per cent (UNCTAD data). Also firm-specific dynamics as retrieved from the data set confirm the positive correlation between the setup of the multilateral EU-CEECs RIA and the undertaking of foreign investments in the periphery, with the total number of MNEs operating in the CEECs in 1999 being 20 times larger than in 1990 (Table 1 , second row). ${ }^{11}$

11 In particular, according to the data set employed in this paper, 75 per cent of FDI initiatives in the considered period come from the EU (from EU multinationals or from US 
Review of World Economics 2007, Vol. 143 (2)

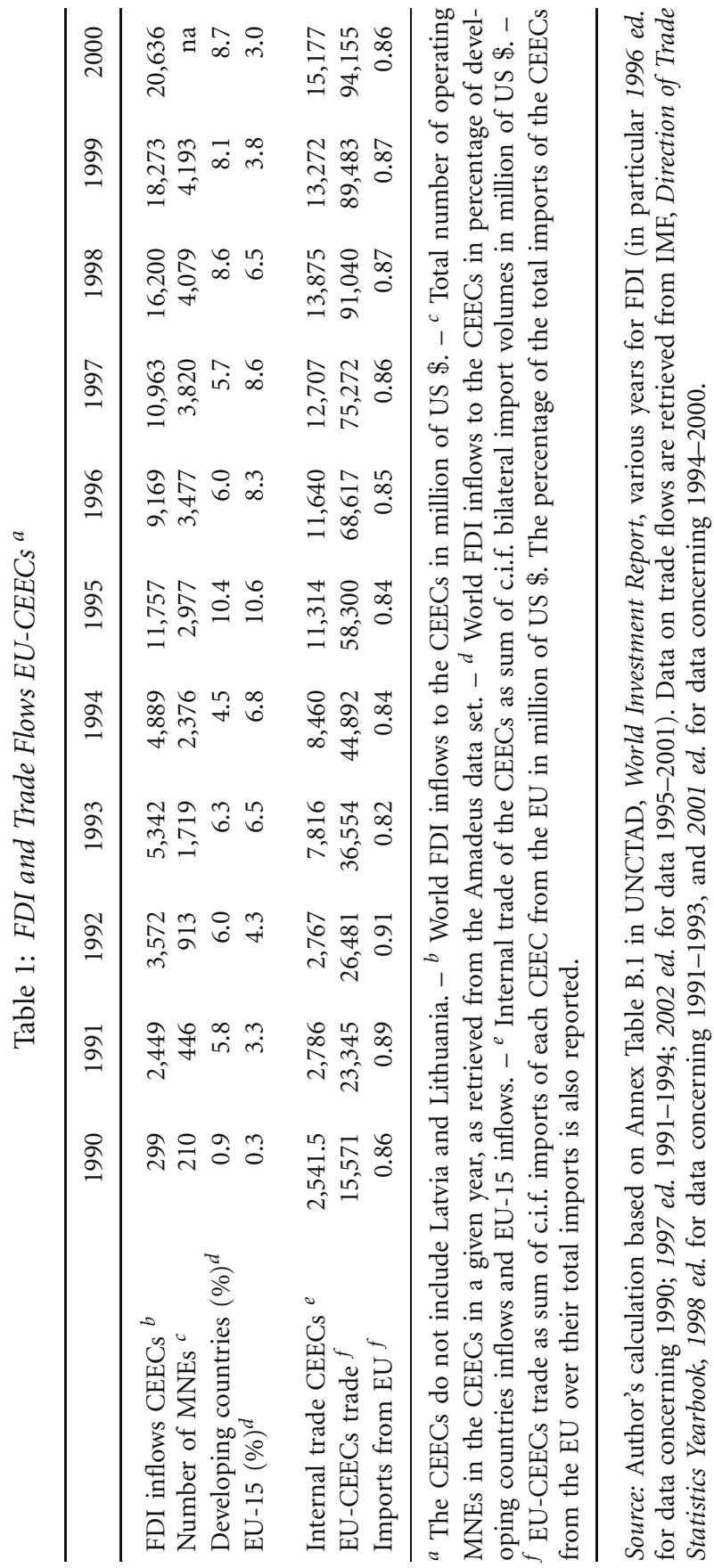


Altomonte: Regional Economic Integration and the Location of Multinational Firms 287

The remarkably parallel behaviour of EU-CEECs trade, internal trade in the CEECs, FDI inflows and the number of MNEs is also confirmed by their correlation coefficients, all above 0.9 and significant at the 1 per cent level, as reported in Table 2.

Table 2: Correlation Coefficients

\begin{tabular}{llllc}
\hline & $\begin{array}{c}\text { Internal trade } \\
\text { CEECs }\end{array}$ & FDI inflows & $\begin{array}{l}\text { Number } \\
\text { of MNEs }\end{array}$ & EU-CEECs trade \\
\hline Internal trade CEECs & 1.0000 & & & \\
FDI inflows & $0.9269^{* * *}$ & 1.0000 & & \\
Number of MNEs & $0.9859^{* * *}$ & $0.9278^{* * *}$ & 1.0000 & \multirow{2}{*}{0.0000} \\
EU-CEECs trade & $0.9626^{* * *}$ & $0.9597^{* * *}$ & $0.9807^{* * *}$ & \\
\hline
\end{tabular}

*** denotes significance at the 1 per cent level.

Source: Author's calculation based on data in Table 1.

Clearly, the above correlations have to be considered as preliminary evidence, since they do not imply any causal relationship. A more informative test of hypothesis can be performed by directly linking the theoretical setup with actual data. In particular, since according to the model the emergence of profit opportunities in the periphery should drive the location choices of MNEs via the increased market access, one can try to measure profits as of (2), and then match them with the actual FDI inflows in the same group of countries. A positive correlation between these two measures would then yield a more robust validation of our hypothesis.

The starting point of analysis is the measure of transport costs, $\tau_{i j}$. The latter term should be time-varying in a process of economic integration, since it incorporates not only 'physical' transport costs, but also the decreasing trade barriers. In order to calculate a dynamic proxy for this term, I have started from the 'gravity' specification of the trade equation, which

MNEs who have invested through their European affiliate), 15 per cent from the US and the remaining 10 per cent from the rest of the world. Official balance of payments figures on FDI volumes would put the EU-US share to 60 vs. 30 per cent, respectively, due to the larger average size of the US affiliates. 
is nested in the demand function employed in the model: ${ }^{12}$

$$
\begin{aligned}
\ln \left(m_{i j t}\right)= & a+\beta_{0} \ln Y_{i t}+\beta_{1} \ln Y_{j t}+\beta_{2} \ln d_{i j} \\
& + \text { border }_{i j}+f t a_{i j t}+\varepsilon_{i j t} .
\end{aligned}
$$

In (3) the (log of) bilateral trade flows $m_{i j t}$ between country $i$ and country $j$ at time $t$ depend positively on the country masses, as proxied by their $(\log )$ GDP denoted by $Y$, and negatively on their geographical distance $d_{i j}$ taken in logs.

The degree of economic integration of country $i$ in the area (its market access $M A$ ) can then be calculated from the estimated coefficients in the gravity equation as $M A_{i}=\sum_{j} d_{i j}^{\hat{\beta}_{2}}$. However, since to this extent it is crucial to obtain an unbiased coefficient for $\hat{\beta}_{2}$, the traditional gravity specification has been improved in a number of ways. First of all, the bilateral component of transportation costs is modelled using data on the distance between capital cities $\left(d_{i j}\right)$ and a dummy for whether an exporting country and importing partner share a common border (border $i j$ ), as in Redding and Venables (2004). More in general, Anderson and van Wincoop (2003) have shown that in order to retrieve a correct specification of the gravity equation it is important to control for unobserved country-specific heterogeneity (what they refer to as the 'multilateral resistance' term), since failing to do so might affect the consistency of the estimates. To avoid this problem, in line with the latest generation of gravity models, I have included country fixedeffects in the estimates. ${ }^{13}$ Moreover, since different countries have entered into regional integration agreements over different years in the sample, I have added a country-pair specific measure of economic integration, namely a dummy ( $f t a)$ that takes value 1 if the pair of considered countries shares a free trade agreement in year $t$, and 0 otherwise.

12 Maximising (1) under the pricing rule, one obtains the equilibrium quantity $q_{i j}=$ $\frac{(\sigma-1)}{\sigma} \frac{\left(\phi_{j} w_{j} \tau_{i j}\right)^{-\sigma}}{\sum_{k} n_{k}\left(\phi_{k} w_{k} \tau_{i k}\right)^{1-\sigma}} M_{i}$ for a representative firm located in $j$ selling in country $i$. Both Redding and Venables (2004) and Head and Mayer (2004) show that the latter can be reinterpreted as the the quantity exported by a representative firm in country $j$ exporting to country $i$. Aggregating $q_{i j}$ across the varieties produced in country $j$ one retrieves, on the left-hand side, the total exports of country $j$ to country $i$. Log-linearizing, the right-hand side can also be rewritten as the sum of a term for each country $i$ and $j$ and a term related to the bilateral market access $\left(\tau_{i j}{ }^{-\sigma}\right)$ between countries. If the latter is proxied by distance and eventually a number of other controls, one retrieves a gravity-like equation.

13 Both Redding and Venables (2004) and Head and Mayer (2004) use country fixedeffects in the different bilateral trade equations they use in order to correctly calculate countries' market accesses. 
Equation (3) has been estimated for the period 1990-2000 using the bilateral trade flows retrieved from the IMF Direction of Trade Statistics (see the Appendix) across the entire EU-CEECs RIA, i.e. among the eight CEECs and between these 'spokes' and the 'hub' (EU), thus yielding a total of $9 \times 8$ country observations for 11 years. The results are reported in columns (1) and (2) of Table 3. As it can be seen, the standard gravity variables are significant and correctly signed. The fta dummy is also significant and positively signed, meaning that, ceteris paribus, a free trade agreement increases trade between the considered country pairs. Moreover, consistent with the theoretical priors, the inclusion of the fta dummy increases the fit of the model and lowers the value of the coefficient of distance, reflecting the idea that, if countries have entered in a process of economic integration, distance tends to measure only pure transport costs (physical distance), rather than trade barriers.

The main problem with the previous specification, however, is that it yields a measure of accessibility which is time-invariant over the considered period, and thus of little use if one wants to explore the impact of a change in the degree of economic integration on the location choices of MNEs. To overcome this problem, I have therefore constructed the following specification of the gravity equation, where a time dummy $T$ is interacted with distance:

$$
\begin{aligned}
\ln \left(m_{i j t}\right)= & a_{i}+\beta_{0} \ln Y_{i t}+\beta_{1} \ln Y_{j t}+\beta_{2} \ln d_{i j}+\beta_{3} \ln d_{i j} T \\
& + \text { border }_{i j}+\varepsilon_{i j t} .
\end{aligned}
$$

This yields $t+1$ estimated coefficients: the static coefficient $\hat{\beta}_{2}$, related to the impact of distance on trade flows, and the coefficients $\hat{\beta}_{3}(t)$, one for each year $t=1990, \ldots, 1999$, measuring the marginal yearly effect of the process of economic integration on the same distance coefficient, an effect entirely captured by the static dummy fta in the previous specification. The estimation of this modified gravity equation are reported in column (3) of Table 3 . As it can be seen, the yearly coefficients of distance are generally significant and decreasing over time, consistent with the empirical evidence of a process of economic integration taking place in the considered region, while the signs and significance of the other gravity variables are robust to this model specification. ${ }^{14}$

14 Technically, it is possible to estimate the model considering only internal trade flows among the CEECs, hence without including the EU. The results obtained, available on re- 
Table 3: Distance Coefficients in a Gravity Equation (Trade Flows within the EU-CEECs Regional Integration Agreement)

\begin{tabular}{lccc}
\hline Variable & $(1)$ & $(2)$ & $(3)$ \\
\hline $\ln Y_{i}$ & $1.28^{* * *}(.183)$ & $.52^{* * *}(.20)$ & $.53^{* *}(.28)$ \\
$\ln Y_{j}$ & $.90^{* * *}(.02)$ & $.83^{* * *}(.02)$ & $.90^{* * *}(.02)$ \\
$\ln d_{i j}$ & $-1.31^{* * *}(.09)$ & $-1.10^{* * *}(.09)$ & $-1.23^{* * *}(.09)$ \\
$\ln d_{i j}-1990$ & - & - & $-.098^{* * *}(.03)$ \\
$\ln d_{i j}-1991$ & - & - & $-.078^{* *}(.03)$ \\
$\ln d_{i j}-1992$ & - & - & $-.150^{* *}(.03)$ \\
$\ln d_{i j}-1993$ & - & - & $-.118^{* * *}(.03)$ \\
$\ln d_{i j}-1994$ & - & - & $-.086^{* * *}(.02)$ \\
$\ln d_{i j}-1995$ & - & - & $-.087^{* * *}(.02)$ \\
$\ln d_{i j}-1996$ & - & - & $-.077^{* * *}(.02)$ \\
$\ln d_{i j}-1997$ & - & - & $-.060^{* * *}(.02)$ \\
$\ln d_{i j}-1998$ & - & - & $-.047^{* *}(.02)$ \\
$\ln d_{i j}-1999$ & - & & $-.056^{* * *}(.02)$ \\
Border & $.32^{* * *}(.11)$ & $.40^{* * *}(.10)$ & $.33^{* * *}(.10)$ \\
fta & - & $.73^{* * *}(.09)$ & - \\
Const. & $-9.72^{* * *}(2.07)$ & $-2.55(2.19)$ & $-1.67(3.09)$ \\
$\mathrm{N}$. of obs. & 693 & 693 & 693 \\
$\mathrm{R}^{2}$ & .81 & .85 & .83 \\
$\mathrm{~F}$ (country coeff.) & $2.27^{* *}$ & $2.16^{* *}$ & $1.63^{*}$ \\
\hline
\end{tabular}

***,**, denote significance at the 1,5 or 10 per cent level respectively.

Note: Panel data estimations with country fixed-effects. Standard errors in parentheses.

From (4) it is then possible to derive a dynamic measure of market access, which can be constructed as follows

$$
M A_{i t}=\sum_{j} d_{i j}^{\hat{\beta}_{2}+\hat{\beta}_{3}(t)} .
$$

Equation (5), being it derived from a gravity specification that controls for individual countries' characteristics, should correctly account for the ongoing process of economic integration. Transport costs $\tau_{i j t}$ can then be

quest, are similar, i.e. decreasing and significant yearly coefficients of distance. This is in line with the reported evidence of the implementation of the CEFTA agreement within the CEECs in the period considered. However, the CEFTA agreement evolves in parallel with the implementation of the bilateral liberalization agreements between each CEEC and the $\mathrm{EU}$ (the area is a multilateral RIA). As a result, if trade flows between the EU and each of the CEECs are not considered in the estimation, this omitted variable (the 'dark mass' of the $\mathrm{EU}$, in the gravity analogy) would bias the results. 
proxied through the reciprocal of the $M A$ value: the higher the degree of integration is, the lower can be considered the transport costs of serving country $i$ from a production plant located in country $j$. Since we are interested in the dynamics of this variable, it is convenient to normalize the market access at time $t$ with respect to its initial value in $t_{0}$ : as market access grows larger over time, the measure of transport costs should tend to zero, and therefore adding one would retrieve the original iceberg formulation of transport costs. ${ }^{15}$ As a result:

$$
\tau_{i j t}=1+\frac{M A_{i t_{0}}}{M A_{i t}} .
$$

Once endowed with this time-varying measure of transport costs, the market potential ( $\sum_{i=1}^{N} \tau_{i j}^{1-\sigma} M_{i}$ in (2) above) can be conveniently proxied in its dynamic form considering

$$
\psi_{j t}=\sum_{i=1}^{N} \tau_{i j t}^{1-\sigma} M_{i t-1}\left(1+g_{i t}\right)
$$

with $M_{i t 0}$ set to a conventional value so as to start from a zero profit condition in $t_{0}$, and $g_{i t}$ equal to the country's (exogenous) growth rate for the considered period. ${ }^{16}$

Equation (2) in the theoretical model states that the profit opportunities available in country $j$ depend on the market potential of country $j$ and a number of dispersion forces, including a measure of the relative costs of country $j$ with respect to the other $N$ countries of the region (i.e. the ratio between the labour costs $\phi_{j} w_{j}$ of country $j$ and those of rival countries $\left.\sum_{k} \phi_{k} w_{k} \tau_{s k}\right)$, and the number of competitors $K=\sum_{k} n_{k}$. As a result, limiting our attention to the profit opportunities emerging in the peripheral countries of the RIA, it is possible to retrieve from macroeconomic aggregates a proxy for local profits as of (2), and then match it with the actual FDI inflows in the same group of countries. ${ }^{17}$

\footnotetext{
15 For simplicity, internal transport costs within countries have not been considered in the calibration, i.e. $\tau_{j j}=1$ for every $t$.

16 Equation (7) implies that the market potential $\psi_{j t}$ of a country $j$ at time $t$ is given by the sum of total expenditures of all countries at time $t$ (calculated as total expenditures at time $t-1, M_{i t-1}$, increased by their growth rates $g_{i t}$ ), times the transport costs $\tau_{i j t}^{1-\sigma}$, always at time $t$.

17 Note that it is always possible to aggregate (2) over a subset of countries pertaining to the considered RIA, without losing the ability of decomposing the same aggregated equation into the three macro variables.
} 
For this purpose, consider these peripheral countries as homogeneous in terms of relative costs (e.g. assume they all have roughly the same labour costs' ratios over time), and concentrate on the effects entailed by the presence of rival firms at time $t$, i.e. $K_{t}$. In particular, following Geroski (1995) and the results of a vast empirical I.O. literature, one can assume the entry of firms $K_{t}$ to be proportional to the expected post-entry profits, typically proxied by lagged profitability $\pi_{t-1}$, net of the costs of entry, here summarized by a parameter $\alpha_{t}$. In other words one can assume an entry rule of the form:

$$
K_{t}=K_{t-1}+\alpha_{t} \pi_{t-1} \text { with } 0<\alpha_{t} \leq 1 .
$$

For given values of the exogenous variables, it is then possible to calculate the evolution of profit opportunities $\pi_{j t}$ arising in all the peripheral countries with the ongoing process of economic integration. In particular, log-linearizing (2) and replacing its static components with their dynamic equivalents, profit opportunities in every year $t$ can be retrieved from (7), which proxy revenues, minus the costs entailed by the presence of competitors $\left(K_{t}\right)$, which evolve according to $(8)$, net of the labour cost ratio, here assumed constant over time and thus excluded from the computation. ${ }^{18}$

More specifically, in order to derive the values of (7), transport costs $\tau_{i j t}$ have been measured through (5) and (6) exploiting the results of the gravity estimation (4); the parameters $g_{i t}$ are the yearly CEECs' growth rates, as retrieved from the World Development Indicators of the World Bank, while the elasticity of substitution has been set at the conventional value $\sigma=5$. The parameter $\alpha_{t}$ of (8), measuring the entry barriers faced by potential investors in the peripheral countries at time $t$, has been proxied through the cross-country average of an index of transition (ori), directly related to the degree to which business operating conditions affect production and profits earned in a local country by a foreign firm. ${ }^{19}$

18 Note that the term $\psi_{j t}$ would affect positively the current profits $\pi_{j t}$ as from (2), while lagged profits $\pi_{j t-1}$ would enter negatively, through the term $K_{t}$, in the determination of $\pi_{j t}$. This implicitly ensures the stability of the dynamic system reported in Figure 1, which will converge to a zero profit condition. The key question is the time span it takes for profit opportunities to be wiped out by the entry of new firms, since as long as profits are positive they will induce a production shifting effect in the RIA.

19 The ORI index is elaborated by BERI s.a., a consultancy firm, through the yearly country ratings reported by a permanent panel of 105 experts around the world. The index takes the values $0-100$, with the last figure indicating ideal business conditions. As a sensitivity check I have also proxied $\alpha_{t}$ with the average percentage of FDI in the region's grossfixed capital formation (GFCF), obtaining similar results in terms of the evolution of profits, although the latter measure might clearly suffer from an endogeneity problem. 
Altomonte: Regional Economic Integration and the Location of Multinational Firms 293

The results of these calculations are reported in Figure 1 for the sum of all CEECs, with initial values $M_{i t 0}$ and $K_{t 0}$ normalized so that in $t_{0}$ a zero profit condition holds, i.e. $\sum_{j} \pi_{j t 0}=0$. As it can be seen, the measure of transport costs as retrieved from (4) to (6) is decreasing over time, in line with the recorded process of economic integration in the area. This has led to an overall increase in the countries' market potential retrieved from (7), which, together with the imperfect nature of entry calculated as from (8), has generated a pattern of positive profit opportunities $\sum_{j} \pi_{j t}$ which have emerged in the periphery (the CEECs) of the newly established multilateral RIA.

Figure 1: Estimated Profit Opportunities in Peripheral Regions (CEECs)

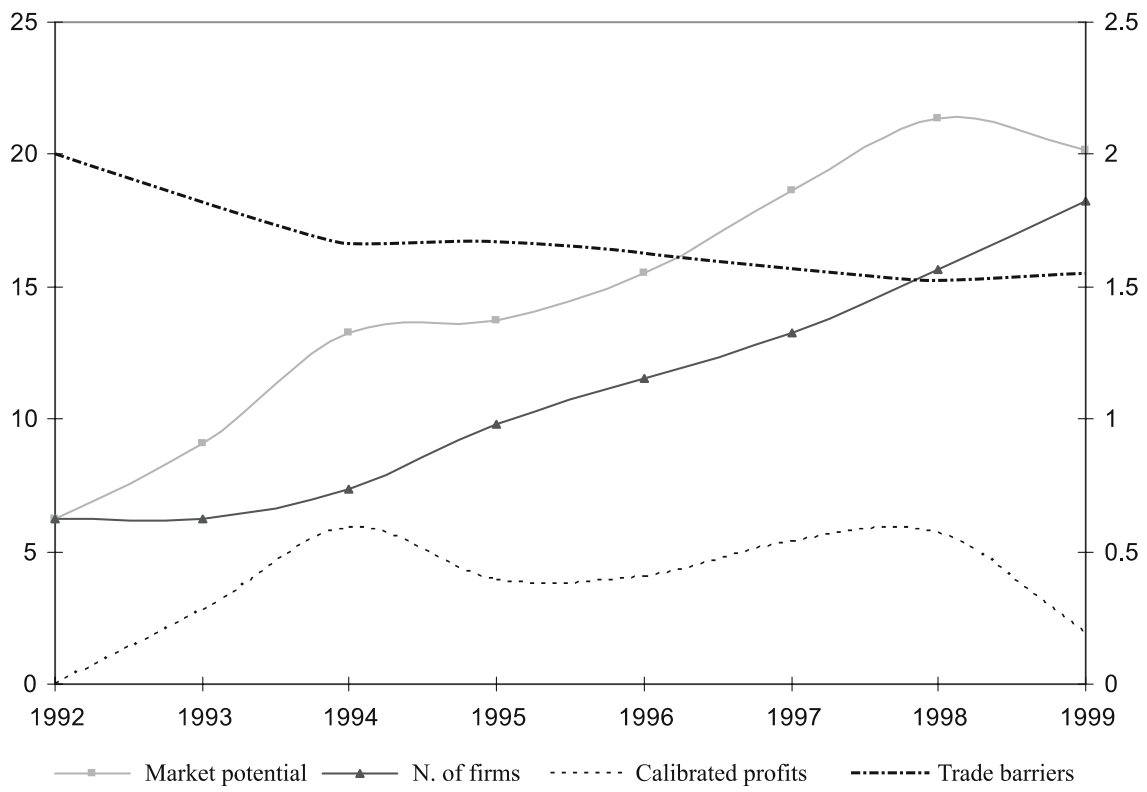

Note: Estimated profits are generated through the methodology reported in Section 3 and measured on the left-hand scale. Trade barriers are measured on the right-hand scale and retrieved from the gravity coefficients of Table 3 via equation (5) and (6). Initial values have been normalized in order to start with a zero profit condition at $t_{0}$.

If the hypothesis on the effects of multilateral RIAs is correct, the dynamics of profits emerging in the peripheral areas of the RIA and resulting from the fitting of the theoretical model should then be correlated with the 
actual location dynamics of FDI inflows experienced in the CEECs. Actually, the correlation between the growth rates of the profits retrieved from the theoretical model (indicated in Figure 1 by the dotted line) and the actual growth rates of MNEs' entry (obtained from Table 1, second row) is 0.89 and significant. A positive, but not significant, correlation has instead been found between the retrieved profits and the actual growth rate of official FDI inflows (based on the data of Table 1, first row).

Hence, in line with the previously discussed hypothesis, we have some evidence that, once controlling for dispersion forces, the increase in market access appears to be the main driving force behind the location of foreign investment in the periphery, rather than in the centre, of the analysed RIA.

Clearly, the reported evidence presented so far has to be checked against a series of potential biases. First of all, when employing official statistics on FDI inflows, the positive but not significant correlation might be induced by industry specific considerations, not present in the growth rates calculated on MNEs' entry. In addition, the exercise has been carried out for the peripheral countries considered jointly (the labour cost ratios have been supposed to be constant across countries and over time), but individual countries' characteristics might act as important dispersion forces within the RIA, and thus have to be taken into account. These concerns are tackled in the next section.

\section{Econometric Analysis}

A more precise link between the establishment of a RIA and the location of FDI in its periphery can be conveniently assessed by constructing an econometric model in which the undertaking of a FDI in a given location is related to the covariates proxying the profit opportunities emerging within the regional integration agreement. To this extent, empirical studies on international location choice increasingly rely on discrete choice (logit) models to test for such a link (Guimarães et al. 2000; Head and Mayer 2004; Barrios et al. 2006). However, a relevant problem posed by discrete choice estimation is the independence of the irrelevant alternatives (IIA): the correct specification of a conditional logit models relies in fact on the assumption that alternatives are symmetric substitutes after controlling for observable characteristics. But the latter hypothesis is clearly at odds in the framework of this paper, where the relevant demand faced by firms in the 
different locations is weighted by a parameter of market access $\left(\tau_{i j}^{1-\sigma}\right)$ which is not symmetric across them.

To control for that, a frequent approach in relaxing the IIA hypothesis is the estimation of a nested logit model, via a partitioning of the alternative choices in mutually exclusive groups which seem to share the same characteristics. The latter approach, however, does not necessarily solve the problem, since in the case of the RIA which encompasses both the EU-15 and the CEECs one should have information on the distribution of the profit functions in all the possible locations, including the 'hub'. That implies to have information on the location choice of firms in the EU-15 countries for the considered period, which is not available with the same detail of analysis.

By using a probit model, instead, one can limit the analysis to the FDI observed in the periphery (the CEECs): if the model is correctly specified and matches actual data, this should result in a significant set of covariates (among which the dispersion forces and the increase in market potential induced by the preferential agreement) affecting the probability of undertaking an investment in the considered countries, without any further assumption on the profit alternatives available in each location.

More specifically, considering the dependent variable $y_{j t}$ which takes value 1 if an investment is registered in the peripheral country $j$ of the RIA at time $t$, and 0 otherwise, on the basis of the theoretical model it is possible to estimate:

$$
\begin{array}{lll}
y_{j t}=1 & \text { if } & \pi_{j t}>\pi_{j t}^{*} \\
y_{j t}=0 & \text { if } & \pi_{j t} \leq \pi_{j t}^{*}
\end{array}
$$

with $\pi_{j t}=\psi_{j t}-K_{t}-\Gamma_{j t}-\varepsilon_{j t}$ retrieved from log-linearising equation (2). In particular, $\psi_{j t}$ is the measure of each country $j$ 's market potential, $K_{t}$ is the number of competitors actually operating in the considered area, and $\Gamma_{j t}$ is a measure of the relative costs of country $j$ with respect to the rest of the area, this time not assumed equal and constant across countries. ${ }^{20}$

Such a model structure might suffer from a number of problems with respect to its error term $\varepsilon_{j t}$, which is likely to be serially correlated with unobserved country characteristics, as well as with an unobserved time trend linked to the ongoing process of economic integration. Moreover, as already

20 As it will be discussed later, the CEECs' labour costs tend to range between 16 and 18 per cent of the EU average for the considered period. 
discussed in the previous section, there is evidence of industry-specific characteristics which might bias the results. Finally, due to the interdependencies of the demand shocks across countries, the error terms might be characterized by an heteroscedastic covariance matrix which expresses a structure of spatial dependence, affecting the efficiency of the OLS estimator and biasing standard errors.

Thanks to the firm-specific nature of the available data set, these problems can be controlled for by allocating each one of the recorded investment operations across countries, industries and years, and by introducing in the estimation country, industry and time fixed-effects, therefore working with a balanced panel, probit model structure. The possible spatial dependence of the estimations' residuals can then be checked through a Moran's I test for spatial autocorrelation (Anselin and Florax 1999). ${ }^{21}$

Hence, the dependent variable of the model $y_{j z t}$ takes the value 1 if an investment is registered in industry $z$ within a given peripheral country $j$ of the considered RIA at time $t$, and 0 otherwise. The total number of $j=1, \ldots, 8$ CEECs, $t=1990, \ldots, 1998$ years and $z=1, \ldots, 48$ industries (all reported in the Appendix) considered in the data set yields therefore a three-dimensional balanced panel of 3,456 observations. Since the aim of the estimation is to link the probability of undertaking a FDI to the profits arising in the different locations (countries), it is convenient to hold industries as the cross-sectional groups, modelling inter-country variability.

The relative costs of each country, the term $\Gamma_{j t}$ in the estimating equation (9), are proxied as the $(\log )$ ratio of the labour costs of country $j$ with respect to the average of the CEECs at time $t .^{22}$ Exploiting the hypothesis of symmetry of firms typical of monopolistic competition, the number of rivals faced by a potential MNE (the term $K_{t}$ ) is measured as the $(\log )$

${ }^{21}$ Note that the balanced panel structure allows for the construction of a $N$ by $N$ spatial weights matrix $W$, where weights are the inverse of distances between countries.

22 The data employed are average monthly gross wages in manufacturing for each country and year, as retrieved from the WIIW Database on Countries in Transition. The comparative advantages of the CEECs should actually be computed including the EU labour costs in the region's average costs. But, while for all the CEECs in the considered period it was possible to retrieve comparable measures of labour costs (gross monthly wages in manufacturing), no similar figure was available for the EU. However, for certain years, Eurostat provides data on monthly gross earnings of full-time employees in industry and services for both the EU and other countries, including most of the CEECs. These data show that the ratio of the CEECs labour costs ranges between 16 and 18 per cent of the EU average and is constant over time for the considered period. As a result, excluding the EU data from the employed measure of comparative advantages is equivalent to discount the same measure by a constant, and hence does not affect the explicative power of the model. 
cumulated number of incumbent MNEs in each industry $z$ at time $t .^{23}$ The hypothesis is that MNEs face competition from all the other foreign firms active in the same industry $z$ across all the CEECs: the assumption is not irrealistic, given that the higher the degree of economic integration across the RIA, the easier it is to serve a location $i$ from other locations $j$ belonging to the RIA. MNEs however do not face competition from domestic firms, an assumption not implausible in transition countries given the initial competitive disadvantage of local producers. ${ }^{24}$

As far as the market potential is concerned, the term $\psi_{j t}$ in (9), the analysis compares three proxies, all varying within the $j$ countries and the $t$ years, in order to explicitly take into account the effects of the changing geographic configuration of the RIA on the location of FDI. A benchmark measure, denoted as $\psi_{j t}(G D P)$, assumes local markets to be segmented at the country level, simply proxying local demand conditions through the (log of) GDP of a country $j$ in each year $t$. A second indicator simulates the effect of a traditional 'hub and spoke' agreement exploiting the original definition of market potential reported by Harris (1954) and generally employed in the literature, considering as the relevant market the GDP of the peripheral country $j$ at time $t$ plus the GDP of the hub country (the EU), always at time $t$, discounted by their bilateral distance, i.e. $\psi_{j t}(h u b-s p o k e)=$ $G D P_{j t}+G D P_{E U t} / d_{i j}$ and taken in logs.

The third measure of market potential employed in the estimation aims at taking into account the multilateral character of the considered RIA. As such, it is retrieved from the theoretical model as $\psi_{j t}(R I A)=\sum_{i=1}^{N+1} \tau_{i j t}^{1-\sigma} M_{i t}$, employing as before the values $\tau_{i j t}$ calculated for $t=1990, \ldots, 1998$ from the gravity equation, taking $\sigma=5$ and proxying $M_{i t}$ with the GDP of each of the $N$ peripheral countries $i$ in year $t$, plus the EU GDP, always discounted by the term $\tau_{i j t}$ derived from the gravity specification.

Industry-, country- and time-specific dummies are included in the estimation, in order to rule out potential problems of spurious correlations between the process of economic integration and FDI inflows. Moreover, since the regression is performed on three-dimensional units (industry, country and year) using mainly industry-invariant variables as covariates,

\footnotetext{
23 In order to take logs, for a matter of convenience the term enters in the estimating equation summing 1 .

${ }^{24}$ Konings (2001) among others reports econometric estimates of the competition effect of MNEs on local firms in transition countries. To the best of my knowledge, no evidence for transition countries exists for competition effects going from local firms to MNEs in the considered period.
} 
I control for the potential downward bias in the estimated errors by clustering the standard errors for all industry groupings. Finally, all the independent variables have been lagged one period with respect to the measurement of FDI to control for simultaneity problems.

Table 4: Econometric Results - Benchmark Models

\begin{tabular}{|c|c|c|c|}
\hline Variable & (1) & (2) & (3) \\
\hline Market potential (GDP) & $\begin{array}{c}1.05^{* * *} \\
(.31)\end{array}$ & - & - \\
\hline Market potential (Hub and Spokes) & - & $\begin{array}{c}1.39^{* * *} \\
(.36)\end{array}$ & - \\
\hline Market potential (Multilateral RIA) & - & - & $\begin{array}{c}2.34^{* * *} \\
(.91)\end{array}$ \\
\hline Number of rivals & $\begin{array}{l}-.12 \\
(.10)\end{array}$ & $\begin{array}{l}-.12 \\
(.10)\end{array}$ & $\begin{array}{l}-.14 \\
(.10)\end{array}$ \\
\hline Relative labour costs & $\begin{array}{c}-.88^{* * *} \\
(.19)\end{array}$ & $\begin{array}{c}-.96^{* * *} \\
(.20)\end{array}$ & $\begin{array}{c}-.55^{* * *} \\
(.16)\end{array}$ \\
\hline 8 country dummies & $173.37^{* * *}$ & $151.57^{* * *}$ & $204.04^{* * *}$ \\
\hline 48 industry dummies & $125.38^{* * *}$ & $125.91^{* * *}$ & $125.45^{* * *}$ \\
\hline 8 time dummies & $186.16^{* * *}$ & $188.52^{* * *}$ & $180.90^{* * *}$ \\
\hline Constant & $\begin{array}{c}-11.58^{* * *} \\
(2.97)\end{array}$ & $\begin{array}{c}-15.17^{* * *} \\
(3.54)\end{array}$ & $\begin{array}{c}-31.59^{* * *} \\
(10.72)\end{array}$ \\
\hline Number of obs. & 2,784 & 2,784 & 2,784 \\
\hline Log-L & $-1,155.53$ & $-1,153.82$ & $-1,156.36$ \\
\hline LR specification test & $209.54^{* * *}$ & $209.48^{* * *}$ & $207.88^{* * *}$ \\
\hline Moran’s I test & $-5.10 \mathrm{e}-05$ & $-5.01 \mathrm{e}-05$ & $-4.47 \mathrm{e}-05$ \\
\hline \multicolumn{4}{|c|}{$\begin{array}{l}\text { ***, }{ }^{* *} \text { denote significance at the } 1 \text { or } 5 \text { per cent level respectively. Dependent variable: pres } \\
\text { ence of FDI in a given industry/country/year. } \\
\text { Note: All covariates lagged one year. Robust standard errors clustered on the industry group } \\
\text { ings in parentheses. The Chi-sq. test of Ho: joint coefficients }=0 \text { is reported for dumm } \\
\text { variables. The specification test is a LR test of the restricted (dummies and constant only } \\
\text { Log-L }=-1,260.30 \text { ) model vs. the unrestricted model. The test statistic is } \chi^{2} \text { distributec } \\
\text { with three degrees of freedom. The Moran's I test for spatial autocorrelation of residuals } \\
\text { two-tail normally distributed (critical value }=1.96 \text { ). }\end{array}$} \\
\hline
\end{tabular}

The results in Table 4 seem to confirm the original intuition of the paper. All the different specifications of the demand variable $\psi_{j t}($.$) are$ positively signed and significant, while relative labour costs are significant and negatively signed, thus acting as dispersion forces in the location of FDI in the area in line with standard results in the literature on international investment. The degree of competition is negatively signed, consistent with 
the theoretical priors, although not significant. Such a result might be due to the nature of the proxy for competition employed in the specification, i.e. the number of incumbent MNEs operating in the same industry in the year before the investment was undertaken, which is also a proxy for agglomeration effects possibly accruing among multinationals. ${ }^{25}$ Finally, country-, industry- and time-specific dummies have always been found significant and jointly different from zero.

The important point to notice for the purpose of this paper emerges when comparing column (3) with columns (1) and (2) of Table 4: when, on top of the traditional 'hub and spoke' configuration of the RIA, all the peripheral countries are included in the calculation of market potential as proxied by the variable $\psi_{j t}(R I A)$, and hence the region is shaped as a multilateral RIA, the demand coefficient gets significantly larger, i.e. the probability of undertaking a FDI in a peripheral country increases significantly. ${ }^{26}$ In this latter case, in fact, the model properly incorporates the entire relevant demand available to the MNEs investing in the peripheral areas, and hence all possible profit opportunities generated from a process of economic integration are duly taken into account, consistent with the emergence of 'complex' integration strategies recently postulated by the FDI literature. The finding thus supports the hypothesis that in multilateral RIAs a second-tier home market effect is less likely to emerge, with the location of FDI taking place also in the periphery of the integrating region.

In terms of specification test, Table 4 reports the LR tests between the log-likelihood of the restricted model (dummies and constant only) and the log-likelihood values of the unrestricted models. ${ }^{27}$ The test statistic is always

25 Head and Mayer (2004) suggest that, once the market potential is included in the estimation, other proxies of agglomeration (as the number of other multinationals employed here) might enter with a negative sign in the estimation to the extent that firms wish to avoid over-crowded markets.

${ }^{26}$ It is worth recalling that in a probit model the $\beta$ coefficients do not measure marginal effects; rather, a unit increase of the independent variable $x_{j z t}$ is such that the score $x_{j z t}^{\prime} \beta$ increases by $\beta$ standard deviations. In order to report marginal probabilities, the change in probability calculated at the mean has to be computed. In the estimated model of Table 4, this yields an increase in the probability of undertaking a FDI of 39 per cent for a unit increase in the $(\log )$ GDP of each country. The probability increases to 51 per cent when the measure of market potential limited to a 'hub and spoke' agreement is considered (column 2), and to 72 per cent when the entire market potential of the multilateral RIA (column 3) is taken into account in the estimation.

27 In particular, as shown in Table 4, the $\chi_{(3)}^{2}$ statistic of the LR specification test is comprised between 212.9 and 208.2 for all the different model specifications, being it significantly larger than the 0.99 per cent critical value of 11.34 . 
Table 5: Econometric Results - Robustness Check

\begin{tabular}{|c|c|c|c|}
\hline Variable & (1) & $(2)$ & (3) \\
\hline Market potential (GDP) & $\begin{array}{l}.84^{* *} \\
(.35)\end{array}$ & - & - \\
\hline Market potential (Hub and Spokes) & - & $\begin{array}{c}1.14^{* *} \\
(.37)\end{array}$ & - \\
\hline Market potential (Multilateral RIA) & - & - & $\begin{array}{c}2.79^{* * *} \\
(.87)\end{array}$ \\
\hline Number of rivals & $\begin{array}{l}-.12 \\
(.10)\end{array}$ & $\begin{array}{l}-.12 \\
(.10)\end{array}$ & $\begin{array}{l}-.14 \\
(.10)\end{array}$ \\
\hline Relative labour costs & $\begin{array}{c}-.87^{* * *} \\
(.20)\end{array}$ & $\begin{array}{c}-.93^{* * *} \\
(.20)\end{array}$ & $\begin{array}{c}-.67^{* * *} \\
(.17)\end{array}$ \\
\hline ORI & $\begin{array}{l}.03^{* *} \\
(.01)\end{array}$ & $\begin{array}{l}.03^{* *} \\
(.02)\end{array}$ & $\begin{array}{l}.03^{* *} \\
(.01)\end{array}$ \\
\hline 8 country dummies & $164.99^{* * *}$ & $140.10^{* * *}$ & $149.56^{* * *}$ \\
\hline 48 industry dummies & $125.92^{* * *}$ & $126.28^{* * *}$ & $127.15^{* * *}$ \\
\hline 8 time dummies & $184.24^{* * *}$ & $187.13^{* * *}$ & $176.19^{* * *}$ \\
\hline Constant & $\begin{array}{c}-10.89^{* * *} \\
(3.22)\end{array}$ & $\begin{array}{c}-13.87^{* * *} \\
(3.49)\end{array}$ & $\begin{array}{c}-39.35^{* * *} \\
(10.83)\end{array}$ \\
\hline Number of obs. & 2,784 & 2,784 & 2,784 \\
\hline Log-L & $-1,153.20$ & $-1,152.10$ & $-1,150.47$ \\
\hline LR specification test & $214.20^{* * *}$ & $215.78^{* * *}$ & $219.66^{* * *}$ \\
\hline Moran's I test & $-5.02 \mathrm{e}-05$ & $-4.98 \mathrm{e}-05$ & $-4.45 \mathrm{e}-05$ \\
\hline \multicolumn{4}{|c|}{$\begin{array}{l}* * *, * * \text { denote significance at the } 1 \text { or } 5 \text { per cent level respectively. Dependent variable: pres } \\
\text { ence of FDI in a given industry/country/year. } \\
\text { Note: All covariates lagged one year. Robust standard errors clustered on the industry group } \\
\text { ings in parentheses. The Chi-sq. test of Ho: joint coefficients }=0 \text { is reported for dumm } \\
\text { variables. The specification test is a LR test of the restricted (dummies and constant onl) } \\
\text { Log-L }=-1,260.30 \text { ) model vs. the unrestricted model. The test statistic is } \chi^{2} \text { distribute } \\
\text { with three degrees of freedom. The Moran's I test for spatial autocorrelation of residuals } \\
\text { two-tail normally distributed (critical value }=1.96 \text { ). }\end{array}$} \\
\hline
\end{tabular}

significant, thus ruling out the hypothesis that the variables postulated by the theoretical model are jointly zero. Moreover, the Moran's I test statistic has always rejected the null of spatial autocorrelation in the different model specifications, which therefore should be characterized by unbiased standard errors.

Table 5 presents a further robustness check of the results, related to the fact that common shocks affecting a given country (such as the implementation of a more liberal FDI legislation, typical of RIAs), if not controlled for in the estimation, might yield a spurious positive correlation between a trade-based indicator of market access and FDI flows. Although country 
fixed-effects have already been taken into account both in the gravity-derived measure of trade integration and in the previous estimates, it is however interesting to include in the estimations the time-varying, country-specific index measuring the quality of the business environment (ori) already employed in the previous section as a proxy for the barriers of entry. The presence of this variable, significant and positively signed as expected, does not seem however to affect the validity of the results derived in the original estimation, as reported in columns (1) to (3) of Table 5.

\section{Conclusions}

This paper tries to reconcile the recorded evidence with the theoretical predictions on the relationship between a process of economic integration and the location of firms. In particular, the paper shows that, once a series of dispersion forces are properly considered within a model of international location, the conventional outcome of an agglomeration of economic activities in the centre of the integrating area does not necessarily hold.

More specifically, the analysis has suggested that a given configuration of regional integration agreements, in which both the traditional 'hub' and the 'spokes' countries mutually liberalize trade (what has been called a 'multilateral' RIA), might act per se as a dispersion force, hindering the emergence of a core-periphery pattern in the integrating area. The intuition is that the creation of a multilateral RIA might allow firms to exploit through the undertaking of FDI the locational advantages of peripheral countries (typically, cheaper factor costs), without necessarily suffering a dramatic reduction in the market size that can be served from these locations. Such a result is in line with the emergence of 'complex' integration strategies recently postulated by the FDI literature.

Clearly, several refinements can be added to the current setup. From a theoretical point of view, the model should be extended to let MNEs arise endogenously in a general equilibrium framework. From a policy-related perspective, the current framework should be tested in the context of multilateral RIAs currently under negotiation, like the future Euro-Mediterranean free trade area, or the FTAA project. The balance of costs and benefits driving the ongoing negotiations migh in fact change significantly, once the possible effects of FDI location arising in the peripheral areas of these perspective RIAs are explicitly taken into account. 


\section{Appendix}

\section{The EU-CEECs Multilateral RIA}

In the early 90s the EU concluded bilateral "Europe Agreements" with the CEECs, removing the standing import quotas on a number of products and progressively establishing free trade in goods and services, with the exception of some agricultural products. At the same time, within the CEECs, two Regional Integration Agreements emerged: the Central European Free Trade Agreement (CEFTA) and the Baltic Free Trade Area (BAFTA).

\begin{tabular}{lccc}
\hline & $\begin{array}{c}\text { Signature of } \\
\text { Europe Agreement }\end{array}$ & $\begin{array}{c}\text { Membership of } \\
\text { CEFTA }\end{array}$ & $\begin{array}{c}\text { Membership of } \\
\text { BAFTA }\end{array}$ \\
\hline Bulgaria & 1 March 1993 & 1 January 1999 & - \\
Czech Rep. & 6 October 1993 & 21 December 1992 & - \\
Estonia & 12 June 1995 & - & 1 April 1994 \\
Hungary & 16 December 1991 & 21 December 1992 & - \\
Latvia & 12 June 1995 & - & 1 April 1994 \\
Lithuania & 12 June 1995 & - & 1 April 1994 \\
Poland & 16 December 1991 & 21 December 1992 & - \\
Romania & 8 February 1993 & 1 July 1997 & - \\
Slovakia & 6 October 1993 & 21 December 1992 & - \\
Slovenia & 10 June 1996 & 1 January 1996 & - \\
\hline
\end{tabular}

\section{Data Sources and the Classification of Industries}

CEECs include: Bulgaria, Czech Republic, Hungary, Estonia, Poland, Romania, Slovak Republic, Slovenia.

GDP data are retrieved from the World Bank, World Development Indicators.

Labour costs (gross monthly wages in manufacturing) are retrieved from the WIIW database on Central and Eastern Europe, with the exclusion of Estonia, where the statistics of the Estonian Statistical Office have been used.

Distance is the quickest street link in km between capital cities, computed through standard route software (MapQuest).

FDI flows are retrieved from Annex Table B.1 in UNCTAD, World Investment Report, various years (in particular $1996 \mathrm{ed}$. for data concerning 1990; $1997 \mathrm{ed}$. 19911994; $2002 \mathrm{ed}$. for data 1995-2001) or, for firm-specific observations of MNEs, from the Amadeus data set, obtaining a sample correlated 0.92 with official FDI flows.

Trade data are c.i.f. bilateral imports retrieved from IMF, Direction of Trade Statistics Yearbook, 1998 ed. for data concerning 1991-1993, and 2001 ed. for data concerning 1994-2000. 
Altomonte: Regional Economic Integration and the Location of Multinational Firms 303

MNEs data are clustered in 48 industries, grouped according to the following NACE 2- and 3-digits classification.

10-11-12-13 and 14 (mining of coal, metals and stone; extraction of petroleum and natural gas); 151 and 152 (production and transformation of meat and fish); 153 and 155 (vegetables, milk and dairy products); 156 (grains); 157 (pet food); 158 (fabrication of bread, tea, coffee and other alimentary products); 159 (drink and beverages); 16 (tobacco); 17 (textiles); 18 (clothing); 19 (leather); 20 (wood); 21 (paper and pulp); 22 (publishing and press); 241 and 242 (basic chemicals and agro-chemicals); 243, 244 and 245 (paintings, pharmaceuticals and soaps and detergents); 246 and 247 (other chemical products and synthetic fibres); 251 (rubber products); 252 and 262 (plastics and ceramics); 26 (other non-metallic products); 27 (metallurgy); 28 (metals); 291 (mechanical machinery); 292 (general machinery); 293 (agricultural machines); 294 and 295 (machine tools); 297 (domestic appliances); 30 (office machines); 31 (electrical appliances, excluding domestic); 321 (electronics); 322 and 323 (communication equipment); 331 and 332 (medical and precision instruments); 334 and 335 (optics, photography, clocks); 341 (car production); 343 (car components); 351 (ship building); 352 and 354 (railways; motorcycles); 361 and 362 (furniture); 363 and 365 (musical instruments and toys); 366 (other general manufacturing); 401 and 402 (electricity and gas); 45 (construction); 55 (hotels and restaurants); 642 (telecommunications); 65 and 66 (financial intermediation and insurance); 72 (computer and related activities); 73 (research and development); 92 (cultural and sporting activities).

\section{References}

Anderson, J. E., and E. van Wincoop (2003). Gravity with Gravitas: A Solution to the Border Puzzle. American Economic Review 93 (1): 170-192.

Anselin, L., and R. Florax (1999). Advances in Spatial Econometrics. Heidelberg: Springer.

Baldwin, R., and A. Venables (1995). Regional Integration Agreements. In G. Grossman and K. Rogoff (eds.), Handbook of International Economics. Vol. III. Amsterdam: Elsevier.

Baldwin, R., R. Forslid, P. Martin, G. Ottaviano, and F. Robert-Nicoud (2003). Economic Geography and Public Policy. Princeton: Princeton University Press.

Baltagi, B., P. Egger, and M. Pfaffermayr (2007). Estimating Models of Complex FDI: Are There Third Country Effects? Journal of Econometrics, forthcoming.

Barrios, S., H. Görg, and E. Strobl (2006). Multinationals' Location Choice, Agglomeration Economies and Public Incentives. International Regional Science Review 29 (1): 81-107.

Blomström, M., and A. Kokko (1997). Regional Integration and Foreign Direct Investment. NBER Working Paper 6019. National Bureau of Economic Research, Cambridge, Mass. 
Carr, D., J. Markusen, and K. Maskus (2001). Estimating the Knowledge-Capital Model of the Multinational Enterprise. American Economic Review 91 (3): 693708.

Carrére, C. (2006). Revisiting the Effects of Regional Trade Agreements on Trade Flows with Proper Specification of the Gravity Model. European Economic Review 50 (2): 223-247.

Davis, D., and D. Weinstein (2003). Market Access, Economic Geography and Comparative Advantage: An Empirical Test. Journal of International Economics 59 (1): 1-23.

Ekholm, K., R. Forslid, and J. Markusen (2003). Export-Platform Foreign Direct Investment. NBER Working Paper 9517. National Bureau of Economic Research, Cambridge, Mass.

Egger, P., and M. Pfaffermayr (2003). The Proper Panel Econometric Specification for the Gravity Equation: A Three-Way Model with Bilateral Interaction Effects. Empirical Economics 28 (3): 571-580.

Geroski, P. A. (1995). What Do We Know About Entry? International Journal of Industrial Organisation 13 (4): 421-440.

Grossman, G., E. Helpman, and A. Szeidl (2006). Optimal Integration Strategies for the Multinational Firm. Journal of International Economics 70 (1): 216-238.

Guimarães, P., O. Figueiredo, and D. Woodward (2000). Agglomeration and the Location of Foreign Direct Investment in Portugal. Journal of Urban Economics 47 (1): 115-135.

Hanson, G. (1996). Economic Integration, Intraindustry Trade and Frontier Regions. European Economic Review 40 (3-5): 941-949.

Hanson, G. (1999). North American Economic Integration and Industry Location. Oxford Review of Economic Policy 14 (2): 30-44.

Harris, C. (1954). The Market as a Factor in the Localization of Industry in the United States. Annals of the Association of American Geographers 44 (4): 315348.

Head, K., and T. Mayer (2004). Market Potential and the Location of Japanese Investment in the European Union. Review of Economics and Statistics 86 (4): 959-972.

Konings, J. (2001). The Effect of Direct Foreign Investment on Domestic Firms: Evidence from Firm Level Panel Data in Emerging Economies. Economics of Transition 9 (3): 619-633.

Markusen, J. (2002). Multinational Firms and the Theory of International Trade. Cambridge: MIT Press.

Markusen, J., and A. Venables (1998). Multinational Firms and the New Trade Theory. Journal of International Economics 46 (2): 183-203.

Markusen, J., and A. Venables (2000). The Theory of Endowment, Intra-Industry and Multi-National Trade. Journal of International Economics 52 (2): 209-234. 
Altomonte: Regional Economic Integration and the Location of Multinational Firms 305

McCallum, J. (1995). National Borders Matter: Canada-U.S. Regional Trade Patterns. American Economic Review 85 (3): 615-623.

Motta, M., and G. Norman (1996). Does Economic Integration Cause Foreign Direct Investment? International Economic Review 37 (4): 757-783.

Nijkamp, P., I. Traistaru, and L. Resmini (2003). The Emerging Economic Geography in EU Accession Countries. London: Ashgate.

Norman, G., and M. Motta (1993). Eastern European Economic Integration and Foreign Direct Investment. Journal of Economics and Management Strategies 2 (4): 483-507.

Puga, D., and A. Venables (1997). Preferential Trading Arrangements and Industrial Location. Journal of International Economics 43 (3-4): 347-368.

Redding, S., and A. Venables (2004). Economic Geography and International Inequality. Journal of International Economics 62 (1): 53-82.

Romalis, J. (2005). NAFTA's and CUSFTA's Impact on International Trade. NBER Working Paper 11059. National Bureau of Economic Research, Cambridge, Mass.

UNCTAD (United Nations Conference on Trade and Development) (2003). FDI Policies for Development: National and International Perspectives. World Investment Report 2003. Geneva: United Nations.

World Bank (various issues). World Development Indicators. Washington, D.C.

Yeaple, S. R. (2003). The Complex Integration Strategies of Multinationals and Cross Country Dependencies in the Structure of Foreign Direct Investment. Journal of International Economics 60 (2): 293-314. 